\title{
LA FALSA DISCROMATOPSIA DEL PINTOR EUGẼNE CARRIÈRE
}

\author{
MIR-FULLANA F ${ }^{1}$
}

Es realmente inusual en un artista de renombre padecer una alteración severa de la visión cromática de tipo congénito. Los que conocen su problema habitualmente evitan trabajar con colores dirigiendo su trayectoria artística hacia otras técnicas como el grabado o la escultura que no precisan una visión cromática normal.

Existe el curioso caso del pintor y litógrafo francés Eugène Carrière (1849-1906), amigo de Rodin y que gozó de una notable fama a finales del siglo XIX (1-3).

Nació en Gournay-sur-Maine en 1849 pero su familia se instaló en Estrasburgo al año siguiente. Era el octavo de nueve hermanos hijos de un modesto agente de seguros, razones suficientes para comprender la situación económica familiar. En contra de los deseos de su padre, inició sus estudios en l'École Municipale de Dessin de Estrasburgo donde aprendió litografía comercial. Más tarde, con la idea de convertirse en pintor, se inscribió en l'École des Beaux-Arts en el taller de Alexandre Cabanel, estudios que fueron interrumpidos por la Gue-

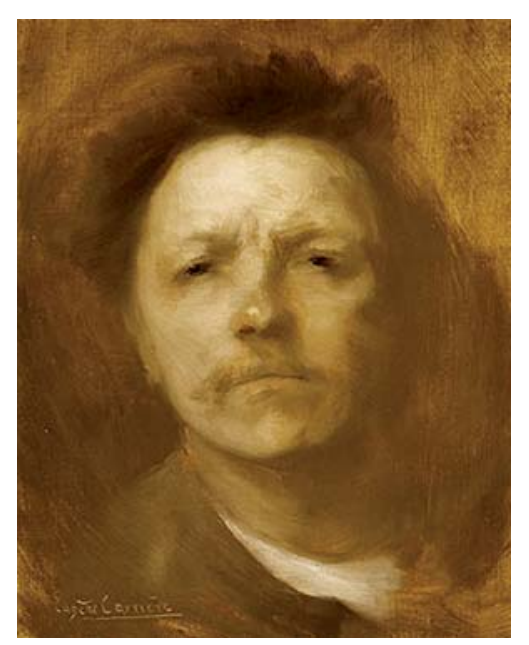

Autorretrato (1893) Metropolitan Museum. rra Franco-Prusiana (1870-1871) en la que participó y fue apresado en Dresde en 1870. Retornó a París trabajando entre el año 1872 y 1873 en el estudio de Jules Cheret (4-5). En 1878 participó por vez primera en el Salon donde su obra pasó desapercibida. Al año siguiente acabó sus estudios con Cabanel, contrayendo matrimonio y viajando a Londres donde pudo admirar la obra de Turner. De regreso a París, hasta 1889 pasó unos años de penurias trabajando ocasionalmente con impresores para alimentar a su familia.

Entre 1880 y 1885 y gracias a su hermano Ernest que era ceramista, trabajó en la fábrica de porcelanas de Sèvres donde conoció a Auguste Rodin iniciándose una estrecha amistad entre los dos artistas.

Las influencias de Cabanel le dieron un estilo en el que se mezclaban los ricos colores de Rubens y Velázquez, pero pronto adoptó un estilo propio cada vez más monocromático y más interesado por las formas que por las líneas jugando con la luz y la sombra. Este personalísimo estilo de colores ocres y terrosos no fue comprendido por el gran público

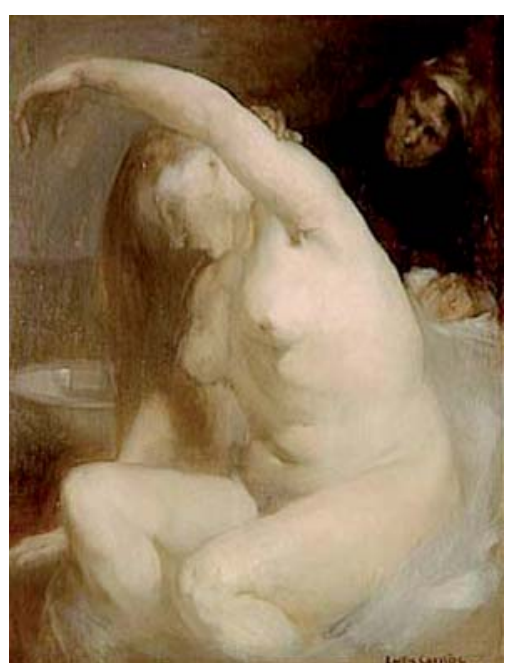

Después del baño - Museo del Louvre.

\footnotetext{
1 Oftalmólogo.

E-mail: Fmir@mutuabalear.es
} 


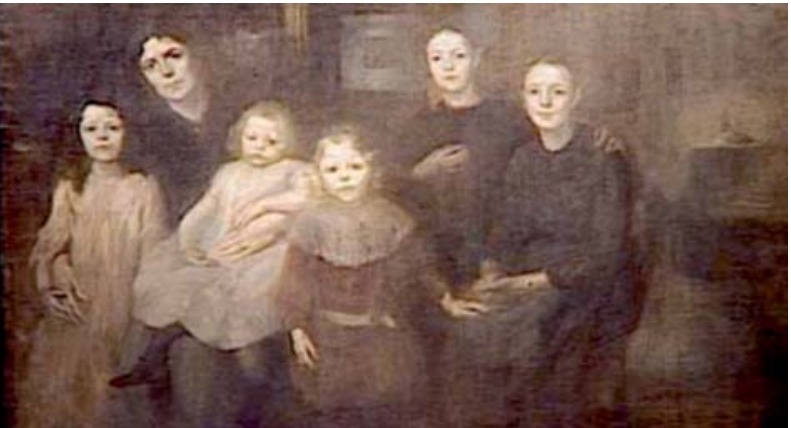

La familia del pintor (1893) Museo Orsay.

pero fue celebrado por Gauguin y Maurice Denis influyendo también en Picasso. Pero nadie como Rodin compartió sus concepciones estéticas y el célebre escultor le confió el cartel y el prefacio del catálogo de su exposición de 1900. A comienzos del siglo XX, Carrière ya era un artista de referencia y daba docencia en su propia academia donde alumnos como Matisse y Derain encontraron la libertad creadora que favoreció su evolución.

Las obras de Eugène Carrière se caracterizan por la distribución monocromática del color donde abundan los marrones, sepias y negros azulados con los contornos de las formas mal delimitados (6) que incluso Degas opinó de ellos: «El modelo se ha movido». Tal vez la mejor definición de su original pintura se debe a Edmond de Goncourt, gran admi-

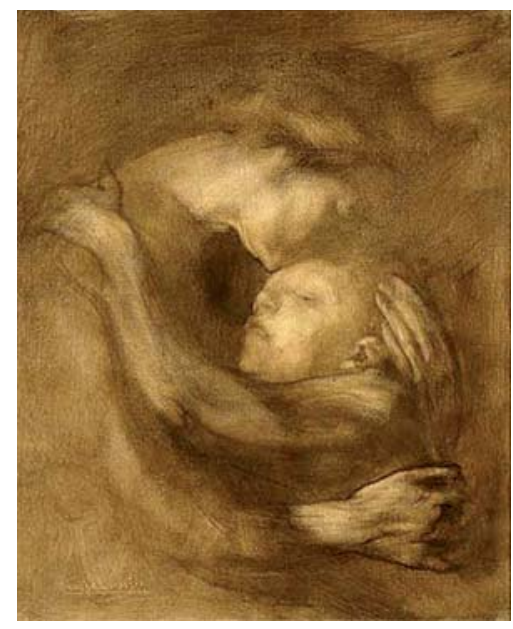

Niño enfermo (1885) Museo Orsay. rador del pintor, que en el año 1889 lo llamó Velázquez crepuscular. Precisamente en el Journal des Goncourt se halla la mayor información sobre Carrière con más de cincuenta y dos citaciones entre los años 1889 y 1896, algunas de ellas de dos y tres páginas.

Estas particulares características cromáticas de sus obras (7), originaron que el oculista Fortín, muy conocido en aquella época por sus investigaciones sobre la retina, declarase que Carrière padecía una acromatopsia y una mala agudeza visual (8).

Se dio la casualidad que el Dr. Polack, eminente especialista de la visión de los colores y muy interesado en la relación entre la pintura y la visión, había examinado al pintor Carrière unos años antes comprobando que tanto su agudeza visual como su visión cromática eran totalmente normales, hecho que lo motivó para publicar un artículo donde desmentía la afirmación de su colega Fortín (9).

A pesar de su documentado informe en una revista médica de la época, la hipótesis sobre la acromatopsia de Carrière, circuló durante décadas y de vez en cuando, esta falsedad resurge en la literatura médica o artística.

Una vez que se extiende una falsedad, la dificultad de demostrar la verdad, aumenta de forma exponencial en el tiempo.

\section{BIBLIOGRAFÍA}

1. Faure E. Eugène Carrière. Peintre et Lithographe. París: H. Floury, 1908.

2. Séailles G. Eugène Carrière, l'homme et l'artiste. París: Pelletan, 1901.

3. Séailles G. Eugène Carrière: essai de biographie psychologique. París: Armand Colin, 1911.

4. Florissone M, Leymarie J. Eugène Carrière et le Symbolisme. París: Edition des Musées Nationaux, 1950.

5. Bantens RJ. Eugène Carrière. The Symbol of Creation. New York: Kent Fine Art, 1990.

6. Bajou V. Eugène Carrière, un nouvel éclairage. Lausanne: Ed Acatos, 1998.

7. Lanthony P. La vision des peintres. Lausanne: L'Âge de l'Homme, 1999.

8. Fortin EP. La vision chez les peintres. Étude physiopathologique. Union Méd Sc Nord-Est 1907; 7: 89-96.

9. Polack A. A propos d'une erreur d'interprétation des oeuvres du peintre Carrière. Chronique Méd 1908; janvier, 29-30. 